遺传学

\title{
人体白血細胞体外受 $\mathrm{X}$ 射綫照射后 染色体畸变的剂量率效应*
}

\author{
䚾安琦周宪庭
}

(中国科学院遭传研究所)

辐射剂量率的改变对于遗传效应是否有 作用是长期以来人们所重视的问题, 因为这 个问题的解决将为辐射遗传的防护研究提供 一些理论基础. 根据经典的辐射遗传学理 论, 点突变以及一次击中的染色体畸变与辐 射剂量是成直线相关的，而且不受刘量率的 影响. 在哺乳动物中研究染色体畸变的刹量 率效应的工作还较少. 过去在植物中研究得 较多.一般认为二次击中的染色体畸变随着 刘量的平方而增加. 然而在很多实验中, 在 低剂量率的情况下半不能得到这样的刘量一 平方关系. Newcombe ${ }^{[1]}$ 提出染色体断裂在 一定的时间內会重合(Restitute). 有重合或省 合系统 (Rejoining system) 存在的理论此后 为 Wolff ${ }^{[2]}$ 等人所进一步证实. 假如在第二 个断裂发生以前第一个断裂已经忿合, 那末 重组性的染色体畸变就不会发生, 因此在低 剂量率的条件下, 畸变就会減低而不能得到 剂量一平方的关系. Brewen ${ }^{[3]}$ 用地鼠眼角膜 上皮细胞的染色体进行实验证明一次击中的 染色体畸变也有刘量率效应, 并且证明这是 由于不同的剂量率对于染色体的愈合系统有 不同程度的作用之故. Bell 和 Baker ${ }^{[4]}$ 用人 体白血细胞进行剂量率效应研究. 他的结果
为仅二次击中畸变有剂量率效应, 而在一次 击中畸变中则没有发现剂量率效应存在.

我们用人体外周血液在体外用不同的剂 量率进行照射, 然后进行白血细胞培养料观 察染色体畸变频率. 照射的刘量率有每分钟 3 伦、31 伦与 202 伦三种. 剂量范围为 $30-$ 240 伦. 照射后所产生的染色体畸变类型除

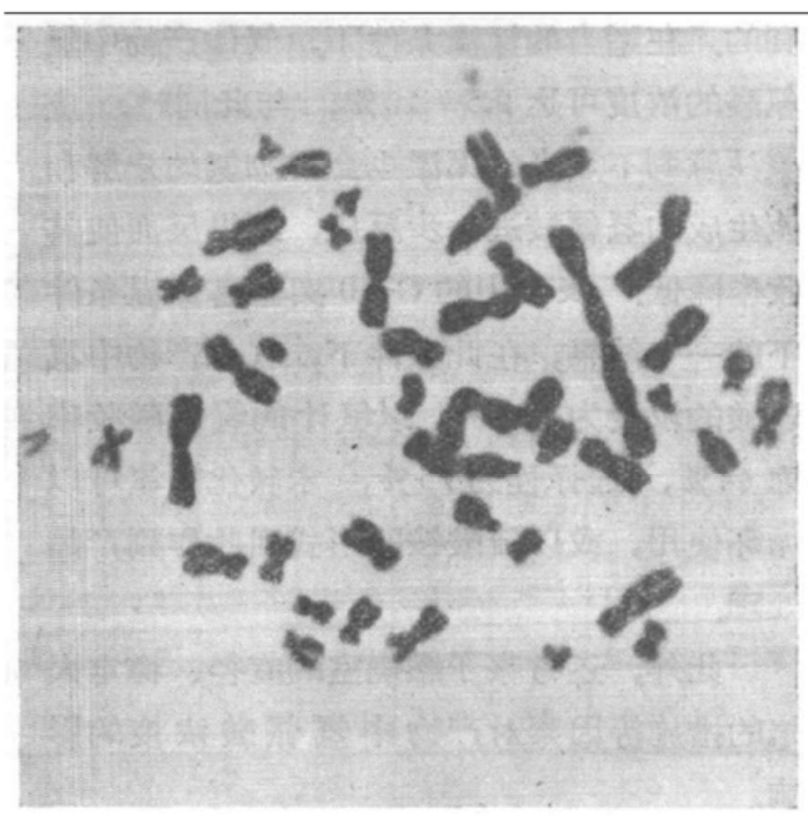

图 1 人体白血细胞受照射后产生的 三着丝点染色体

* 本工作初步结果管在中国动物学会三十周年年会上 宣读. 
作者前交 ${ }^{[5]}$ 所述者外还有三着丝点（图 1). 根据协方差分析结果, 说明无论是以总的染 色体断裂数计、一次击中的畸变计，或者以 二次击中的畸变计，在斺量率每分钟 31 伦 与每分钟 202 伦所产生的晻变频率之间都有 显著性差异。換言之，不论是一大击中的畸 变或是二次击中的畸变在一定范围內都有刘 量率效应. 实验数据经过配线及显著性检验 后, 说明二次击中畸变和一次击中畸变在高 剂量率时都显示出刘量一平方关系，在较低 剂量率下, 剂量一平方关系不显著, 虽然也 有曲线的趋势 (图 2、3).

本实验在人体细胞中直接证明了在一定 范围內減低刘量率可以娍低各种类型的染色

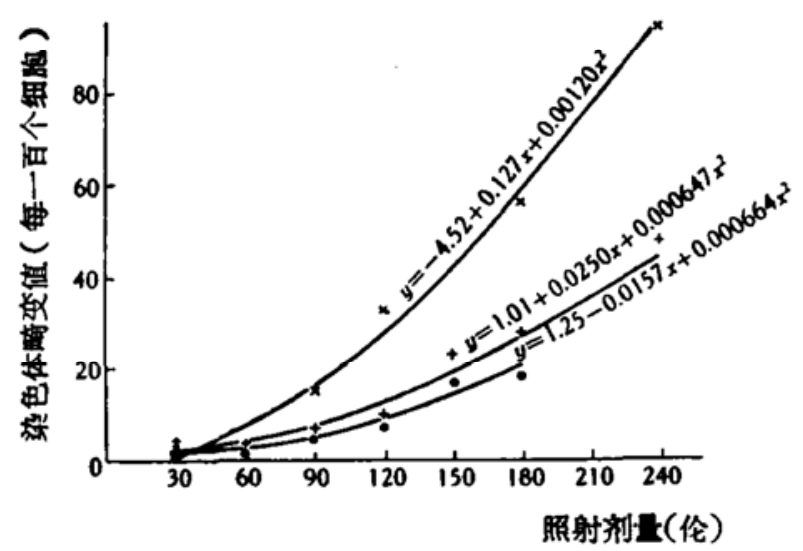

图 2 一头击中染色体猗变值对 $\mathrm{x}$ 射线削量的回归线

$\times$ 剂量軍 $202 \mathrm{r} / \mathrm{min}$

+ 剂量率 $31 \mathrm{r} / \mathrm{min}$

- 剂至事 $3 \mathrm{r} / \mathrm{min}$

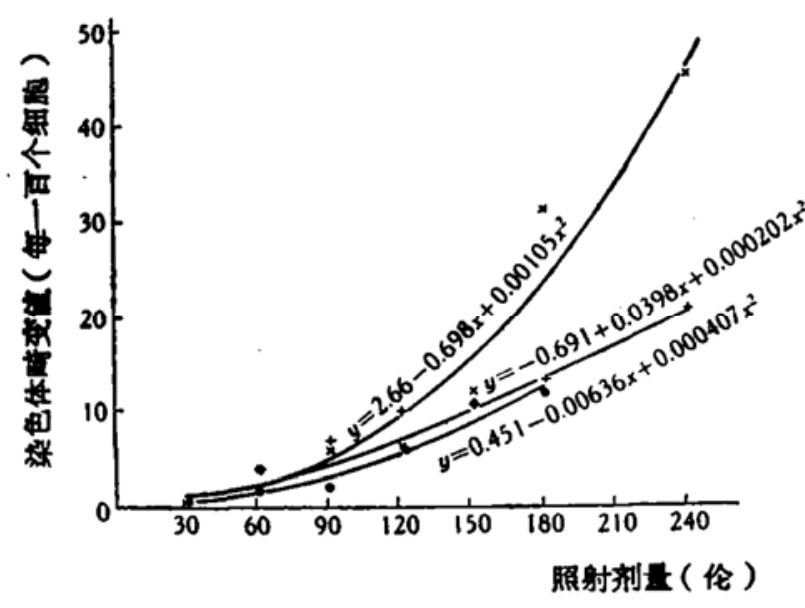

图 3 二头击中染色体猗变值对 $\mathrm{X}$ 射线制兵的回归线

$\times$ 剂至高 $202 \mathrm{r} / \mathrm{min}$

+ 判年事 $31 \mathrm{r} / \mathrm{min}$

- 剂岳事 $3 \mathrm{r} / \mathrm{min}$

体畸变频率, 为辐射防护的研究提供了一些 资料.

志淤: 工作中承中国科学院生物物理研究所提 供唱射条件. 文中生物绕计分析得到杨纪珂敬授指 导; 宁篮华同志去加本工作, 特此致期.

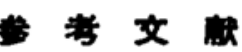

[1] Newcombe, H. B., J. Genet., 43, 237-248 (1942).

[2] Wolff, S. \& Luippold, H. E., The Biochemical Aspects of Chromosome Rejoining, in Progress in Radiobiology (edited by Mitchell, S. S. et al.), 217 (1956), Edingburh: Oliver and Boyd.

[3] Brewen, J. G., Proc. Nat. Acad. Sci., 50, 322329 (1963).

[4] Bell, A. G. \& Baker, D. G., Canad. J. Genet., 4, 340-351 (1962).

[ 5] 汪安瑷、周宪庭, 实验生物学报, 9 [2], 178-183 (1964). 